\title{
Epidemiology of Hepatitis B in the Reproductive-Age Female Farmworkers of Southeastern Turkey
}

\author{
Nebiye Yentur Doni ${ }^{1,} ;$ Zeynep Simsek $^{2}$; Zehra Keklik ${ }^{2}$; Gulcan Gurses ${ }^{1} ;$ Fadile Yildiz Zeyrek $^{3}$ \\ ${ }_{1}^{1}$ Department of Medical Microbiology, Vocational School of Health Services, Harran University, Sanliurfa, Turkey \\ ${ }_{2}^{2}$ Department of Public Health, Faculty of Medicine, Harran University, Sanliurfa, Turkey \\ 3 Department of Medical Microbiology, Faculty of Medicine, Harran University, Sanliurfa, Turkey \\ ${ }^{*}$ Corresponding Author: Nebiye Yentur Doni, Department of Medical Microbiology, Vocational School of Health Services, Harran University, Sanliurfa, Turkey. Tel: +90-4143183212, Fax:
} +90-4143183211, E-mail:n_doni@hotmail.com

Received: July 17, 2014; Revised: September 26, 2014; Accepted: October 24, 2014

\begin{abstract}
Background: There are limited data on the prevalence of the hepatitis B virus (HBV) infection in the agricultural population worldwide. Objectives: This study aimed to determine the prevalence of HBV infection and associated risk factors in the reproductive-age female farmworker.

Materials and Methods: This cross-sectional study was conducted between January and April 2013 in southeastern region(SAR) of Turkey. A community-based representative agricultural sample $(n=705)$ from the agricultural areas of nine provinces of SAR was randomly determined by clustering method using Epi Info software. Questionnaires including demographic information and risk factors of HBV were administered to participants. The presence of $\mathrm{HBsAg}$, anti-HBs, anti-HBc, and anti-HBe antibodies in blood samples were measured by ELISA.

Results: The prevalence of the HBsAg, anti-HBs, anti-HBc, anti-HBe antibodies, and seropositivity were 5.7\%, 25.9\%, 28.9\%, 16.4\%, and 36.7\%, respectively. There was no association between the HBsAg and the size of the household, age, education level, parity, and place of birth while the prevalence of HBsAg was higher in seasonal migratory farmworkers and people living in urban areas and the prevalence of anti-HBs antibody was significantly higher in women $\geq 35$ years of age, those with a high parity, and those who gave birth without the assistance of health professionals $(\mathrm{P}<0.05)$. The risk for $\mathrm{HBV}$ infection in the seasonal migratory group was 4.3 times higher in comparison to local workers $(\mathrm{P}=0.00 ; \mathrm{OR}=4.3 ; 95 \% \mathrm{CI}, 2.2-8.4)$, with a prevalence rate of $11 \%$.

Conclusions: The monitoring of at-risk groups like seasonal migratory farmworkers is necessary to strengthen the healthcare service provided to this population.
\end{abstract}

Keywords:HBsAg; ELISA; Agriculture

\section{Background}

The hepatitis B virus (HBV) causes hepatitis B and is a serious and common infectious disease with a worldwide distribution. According to World Health Organization (WHO) data, it is estimated that more than two billion people have been infected with the HBV worldwide. Of these, globally, around 240 million people are chronically infected and are at risk of serious illness and death, mainly from liver cirrhosis and hepatocellular carcinoma $(1,2)$. Mathematic modelling for the year 2000 estimated the number of deaths from HBV-related diseases at between 500000 and 700000 deaths each year (3). The highest hepatitis B surface antigen (HBsAg) carrier rates were found in developing countries with primitive or limited medical facilities $(4,5)$. In the WHO European region, over 13 million adults are living with hepatitis $B$ (1). In southeastern Asia, it is estimated that 160 million people have chronic HBV infections and annually more than 360000 HBV-related deaths occur (3). The endemicity of hepatitis $\mathrm{B}$, which is described by the prevalence of HBsAg in the general population of a defined geo- graphical area, varies considerably regarding geographic region. HBsAg prevalence of $>8 \%$ is typical of highly-endemic areas and prevalence of $2 \%$ to $7 \%$ is found in areas of intermediate endemicity, whereas in areas with low endemicity, $<2 \%$ of the population is HBsAg-positive. Turkey is located in an endemic region with an intermediate prevalence of HBV (2). In a meta-analysis consisting of seroprevalence studies published between 1999 and 2009, the overall population HBsAg prevalence was estimated at $4.6 \%$ in Turkey and approximately 3.3 million people were determined as chronic hepatitis B cases (6). According to the International Labour Organization, agriculture is the second greatest source of employment worldwide, with over one-third of the world's workforce (1.3 billion people) depending on agriculture. Agriculture is the most important sector for female employment in many countries, and especially in Africa and Asia (7). In Turkey, 24.6\% (6.143 million people) of the labor force are employed in the agriculture sector (8). Agriculture is one of the three most hazardous sectors in the world (the

Copyright (C) 2014, Kowsar Corp. This is an open-access article distributed under the terms of the Creative Commons Attribution-NonCommercial 4.0 International License (http://creativecommons.org/licenses/by-nc/4.0/) which permits copy and redistribute the material just in noncommercial usages, provided the original work is properly cited. 
other being mining and construction) (7). According to WHO data, living in or travelling to regions with endemic hepatitis B are considered as risk factors for HBV (9). The female farmworkers' settlements and living conditions are unhealthy; these women and their families live in crowded conditions and poverty, with poor hygienic conditions, under poor sanitation, and limited healthcare services. The farmworkers' risk of contracting hepatitis B is unknown in the Southeastern Anatolia Project (GAP) region. It is required to investigate the prevalence and risk factors affecting hepatitis B infection in this undeserved people. Although the majority of previous studies on the frequency of HBV have analyzed data obtained from blood donors, pregnant women, and medical personnel $(10,11)$, there are limited studies on reproductive-age female farmworkers. It is important to study these women with hepatitis B, because their newborn children are a potential risk group.

\section{Objectives}

The objective of this cross-sectional study was to determine the prevalence and risk factors of HBV markers among reproductive-age female farmworkers in the GAP region, in order to address future prevention and control activities.

\section{Materials and Methods}

\subsection{Study Area}

This study was conducted between January and April 2013, in the nine GAP provinces (Adiyaman, Batman, Diyarbakır, Gaziantep, Kilis, Mardin, Siirt, Sanliurfa, and Sirnak). According to the 2012 census records, the total population of the GAP region was approximately 7816173 (nearly one-tenth of the total Turkish population), where $25 \%$ of the population were employed in agriculture and $49.5 \%$ of the agriculture workers were women (12). The GAP region is one of the least developed regions of Turkey.

\subsection{Study Design}

In this study, hepatitis B variables from the representative multipurpose cross-sectional research data of the GAP Agricultural Health Survey/2013, conducted by the authors in collaboration with the Harran University Scientific Research Council and GAP Regional Development Administration, were analyzed. This survey was approved by the Ethics Committee of the Faculty of Medicine at Harran University. The sample size was calculated at 1200 households (95\% confidence level, 5\% confidence interval $[\mathrm{CI}]$ with design effect of 1.2) using probability proportional to size method by The National Turkish Statistics Institution. The cluster size was determined as ten households working in agriculture. The houses were numbered from one to ten; households were chosen by using a table of random digits. One woman aged 15 to 49 years old, who was able to provide informed consent and was eager to give blood sample, was chosen randomly in each house by person selection method. We excluded the women who had intellectual disabilities. Working in agriculture and animal husbandry was determined in 1128 households. A total of 137 women (12.1\%) were reluctant to participate in the study or refused to a give blood sample, 41 of which (3.6\%) could not be located during home visits, and there was no appropriate person to interview in seven households (0.6\%). Therefore, this study was successfully conducted in 705 households with the response rate of $75 \%$. During home visits, the aim of the study was explained to the participants and informed consent was obtained from each participant. Data were collected during a face-to-face interview using a structured questionnaire that included sociodemographic information on family size, age, education level, type of work (seasonal migratory worker vs. family farmer), type of settlement, number of pregnancies (parity), and delivery.

\subsection{Blood Samples and Serologic Markers}

Blood samples were drawn from female farmworkers aged between 15 and 49 years and kept in gel vacuum tubes. The tubes containing the blood were labeled and transferred to the Harran University Microbiology Laboratory under suitable conditions. The samples were centrifuged and stored at $-80^{\circ} \mathrm{C}$ until further use. The sera were tested for HBsAg, hepatitis B surface antibodies (anti-HBs), hepatitis B core antibodies (anti-HBc), and antibodies against hepatitis B e antigen (anti-HBe) using the enzyme-linked immunosorbent assay (Abbott Architect, Abbott Laboratories, IN, USA). We tested each control for these tests once in every 24 hours and paid attention for control values to be within the ranges specified in the control package insert. We calibrated the device according to the manufacturer's instructions for HBsAg, anti-HBs, anti$\mathrm{HBC}$, and anti-HBe. The ARCHITECT qualitative serological assay (HBsAg, anti-HBs, anti-HBc, and anti-HBe) calculated a result based on $s$ ample relative light unit (RLU)/Cutoff RLU (S/CO). Specimens with S/CO values $<1.00$ were considered nonreactive for $\mathrm{HBs}$, anti-HBc, and anti-HBe assays and did not need undergoing further test. Specimens with $S / C O$ values $\geq 1.00$ were considered reactive for $\mathrm{HBs}$, anti$\mathrm{HBc}$, and anti-HBe assays. Specimens with concentration values $<10.00 \mathrm{mIU} / \mathrm{mL}$ were considered nonreactive and $\geq 10.00 \mathrm{mIU} / \mathrm{mL}$ as reactive for anti-HBs. The diagnosis of hepatitis B is confirmed by demonstration of specific antigens and/or antibodies in the sera. The presence of HBsAg indicates that the person is potentially infected $(4,13,14)$. Anti-HBs generally persists for a patients' lifetime in over $80 \%$ of cases and indicates immunity $(4,13,14)$. Anti-HBc is the first antibody to appear. Demonstration of anti-HBC in the serum indicates current or previous $\mathrm{HBV}$ infection. Anti-HBe appears after anti-HBc and its presence correlates with a decreased infectivity. Anti-HBe replaces HBeAg in the resolution of the disease $(4,13,14)$. 


\subsection{Statistical Analysis}

Data entry and analyses were performed using SPSS 11.5 (SPSS Inc., Chicago, IL. USA). After determining the association factors in a bivariate analysis, logistic regression was used to control the confounder and to calculate adjusted odds ratios (OR) (95\% CI). All of the statistical tests were two-tailed and differences were considered significant at $P$ value $<0.05$.

\section{Results}

A total of 705 reproductive-age female farmworkers, with a mean age of $36.16 \pm 9.79$ years and a mean household size of $8.12 \pm 0.12$, were enrolled in this study. Approximately, $64 \%$ of the participants had seven or more family members, $54.5 \%$ were $>35$ years old, $68.1 \%$ were illiterate, $34.8 \%$ were seasonal migratory farmworkers, $58.4 \%$ had $\geq$ 5 children, and $61.2 \%$ had given a birth without the aid of healthcare professionals. The prevalence rates of the HBsAg, anti-HBs, anti-HBc, anti-HBe, and seropositivity were $5.7 \%, 25.9 \%, 28.9 \%, 16.4 \%$, and $36.7 \%$, respectively (Table 1 ). Anti-HBc and anti-HBe were detected in 32 and 30 HBsAg seropositive females ( $80 \%$ and $75 \%$, respectively).

As seen in Table 2, while there was no significant association between HBsAg positivity and the size of the household, age group, education level, number of pregnancies, and place of birth $(\mathrm{P}>0.05)$. Type of work and settlement were significantly associated with HBsAg positivity. HBsAg positivity was determined as $11 \%$ among migratory seasonal female farmworkers and $2.8 \%$ among female family farmworkers. According to logistic regression analyses (Table 3), HBsAg positivity was 4.2 times higher among seasonal female farmworkers than among female family farmworkers (95\% Cl, 2.1-8.2); HBsAg seropositivity was also higher among women living slums of the urban area than among those living in rural areas $(\mathrm{OR}=2.0 ; 95 \%$ $\mathrm{Cl}, 1.04-3.95)$.

Table 1. Prevalence Rates of the Seropositivity for Hepatitis B Virus Markers in the Southeastern Anatolia Project Region of Turkey, in 2013

\begin{tabular}{lc}
\hline Variables & No.(\%) \\
\hline HBsAg Positivity & $40(5.7)$ \\
\hline Anti-HBs Positivity & $182(25.9)$ \\
\hline Anti-HBc Positivity & $204(28.9)$ \\
\hline Anti-HBe Positivity & $116(16.4)$ \\
\hline Seropositivity & $176(25.1)$ \\
\hline HBsAg Positivity Total & $40(100)$ \\
\hline $\begin{array}{l}\text { Anti-HBc Positivity in Cases } \\
\text { With HBsAg Positivity }\end{array}$ & $32(80)$ \\
\hline $\begin{array}{l}\text { Anti-HBe Positivity in Cases } \\
\text { With HBsAg Positivity }\end{array}$ & $30(75)$ \\
\hline
\end{tabular}

\begin{tabular}{|c|c|c|c|c|}
\hline Variables & HBsAg (+) & HBsAg (-) & Total & $\mathrm{X}^{2}$; P; Crude Odds Ratio $(95 \% \mathrm{Cl})$ \\
\hline \multicolumn{5}{|l|}{ Household Size } \\
\hline$\leq 6$ & $16(6.4)$ & $235(93.6)$ & $251(35.6)$ & $0.157 ; 0.69 ; 1.1(0.6-2.2)$ \\
\hline$\geq 7$ & $24(5.3)$ & $430(94.7)$ & $454(64.4)$ & \\
\hline \multicolumn{5}{|l|}{ Age Groups } \\
\hline$\leq 34 \mathrm{y}$ & $17(5.3)$ & $304(94.7)$ & $321(45.5)$ & $0.157 ; 0.69 ; 1.1(0.6-2.2)$ \\
\hline$\geq 35 \mathrm{y}$ & $23(6.0)$ & $361(94.0)$ & $384(54.5)$ & \\
\hline \multicolumn{5}{|l|}{ Education Level } \\
\hline Illiterate & $26(5.6)$ & $445(94.5)$ & $471(68.1)$ & $0.18 ; 0.67 ; 1.2(0.6-2.3)$ \\
\hline Primary School or Higher & $14(6.4)$ & $206(93.6)$ & $220(31.9)$ & \\
\hline \multicolumn{5}{|l|}{ Type of Work } \\
\hline Family Farmers & $13(2.8)$ & $447(97.2)$ & $460(65.2)$ & $20.05 ; 0.00 ; 4.3(2.2-8.4)$ \\
\hline Seasonal Migratory Workers & $27(11.0)$ & $218(89.0)$ & $245(34.8)$ & \\
\hline \multicolumn{5}{|l|}{ Type of Settlement } \\
\hline Rural Area & $15(3.9)$ & $373(96.1)$ & $388(55.0)$ & $5.26 ; 0.022 ; 2.0(1.1-3.8)$ \\
\hline Slum in Urban Area & $25(7.9)$ & $292(92.1)$ & $317(45.0)$ & \\
\hline \multicolumn{5}{|l|}{ Number of Pregnancies (Parity) } \\
\hline$\leq 4$ & $13(4.4)$ & $280(95.6)$ & $293(41.6)$ & $1.43 ; 0.15 ; 1.5(0.8-2.9)$ \\
\hline$\geq 5$ & $27(6.6)$ & $385(93.4)$ & $411(58.4)$ & \\
\hline \multicolumn{5}{|l|}{ Place of Delivery } \\
\hline Birth at a Healthcare Center & $13(5.0)$ & $246(95.0)$ & $259(38.8)$ & $0.71 ; 0.40 ; 1.32(0.70-2.50)$ \\
\hline $\begin{array}{l}\text { Birth at Home Without Health } \\
\text { Professionals Aid }\end{array}$ & $27(6.6)$ & $382(93.4)$ & $409(61.2)$ & \\
\hline Total & $40(5.7)$ & $665(94.3)$ & $705(100.0)$ & \\
\hline
\end{tabular}

\footnotetext{
${ }^{\mathrm{a}}$ Data are presented as No. (\%).
} 
Yentur Doni N et al.

\begin{tabular}{|c|c|c|c|c|c|c|c|}
\hline \multirow[t]{2}{*}{ Independent Variables } & \multirow[t]{2}{*}{ B } & \multirow[t]{2}{*}{ SE } & \multirow[t]{2}{*}{ Wald } & \multirow[t]{2}{*}{ P Value } & \multirow[t]{2}{*}{ EX $(B)$} & \multicolumn{2}{|c|}{ CI 95\% } \\
\hline & & & & & & Lower & Upper \\
\hline $\begin{array}{l}\text { Type of Work (Seasonal } \\
\text { Farmworkers) }\end{array}$ & 1.424 & 0.349 & 16.684 & 0.000 & 4.15 & 2.08 & 8.23 \\
\hline $\begin{array}{l}\text { Type of Settlement (Living } \\
\text { in Slums) }\end{array}$ & 0.707 & 0.340 & 4.320 & 0.038 & 2.029 & 1.04 & 3.95 \\
\hline Constant & -3.902 & 0.348 & 126.038 & 0.000 & & & \\
\hline
\end{tabular}

Table 4. Anti-HBs Positivity According to Selected Independent Variables a

\begin{tabular}{|c|c|c|c|c|}
\hline Variables & Anti-HBs (+) & Anti-HBsAg (-) & Total & $\mathrm{X}^{2}$; P; Crude Odds Ratio (95\% Cl) \\
\hline \multicolumn{5}{|l|}{ Household size } \\
\hline$\leq 6$ & $68(27.1)$ & & $251(356)$ & $0.313 ; 0.57 ; 1.01(0.8-1.3$ \\
\hline$\geq 7$ & $114(25.2)$ & & $454(644)$ & \\
\hline \multicolumn{5}{|l|}{ Age Groups } \\
\hline$\leq 34 \mathrm{y}$ & $68(21.3)$ & $253(78.7)$ & $321(45.5)$ & $6.48 ; 0.011 ; 1.6(1.1-2.2)$ \\
\hline$\geq 35 \mathrm{y}$ & $114(29.7)$ & $270(70.3)$ & $384(54.5)$ & \\
\hline \multicolumn{5}{|l|}{ Education Level } \\
\hline Illiterate & $132(28.2)$ & $338(71.8)$ & $471(68.1)$ & $2.76 ; 0.096 ; 0.7(0.5-1.1)$ \\
\hline Primary School or Higher & $49(22.3$ & $171(77.7)$ & $220(31.9)$ & \\
\hline \multicolumn{5}{|l|}{ Type of Work } \\
\hline Family Farmers & $113(24.6)$ & $347(75.4)$ & $460(65.2)$ & $1.14 ; 0.28 ; 1.2(0.9-1.7)$ \\
\hline Seasonal Migratory Workers & $69(28.3)$ & $175(71.7)$ & $245(34.8)$ & \\
\hline \multicolumn{5}{|l|}{ Type of Settlement } \\
\hline Rural Area & $97(25.1)$ & $290(74.9)$ & $388(55.0)$ & $0.27 ; 0.59 ; 0.9(0.7-1.3)$ \\
\hline Slum in Urban Area & $85(26.8)$ & $232(73.2)$ & $317(45.0)$ & \\
\hline \multicolumn{5}{|l|}{ Number of Pregnancies (Parity) } \\
\hline$\leq 4$ & $61(20.8)$ & $232(79.2)$ & $293(41.6)$ & $6.63 ; 0.010 ; 1.6(1.1-2.3)$ \\
\hline$\geq 5$ & $121(29.4)$ & $290(70.6)$ & $411(58.4)$ & \\
\hline \multicolumn{5}{|l|}{ Place of Delivery } \\
\hline Birth at a Healthcare Center & $50(19.3)$ & $209(80.7)$ & $259(38.8)$ & $8.145 ; 0.004 ; 1.7(1.2-2.6)$ \\
\hline $\begin{array}{l}\text { Birth at Home Without Healthcare } \\
\text { Professionals Aid }\end{array}$ & $119(29.2)$ & $289(70.8)$ & $409(61.2)$ & \\
\hline Total & $182(25.9)$ & $523(74.1)$ & $705(100.0)$ & \\
\hline
\end{tabular}

a Data are presented as No. (\%).

As seen in Table 4, the bivariate analyses revealed significant associations between anti-HBs positivity and age, parity, and place of delivery $(\mathrm{P}<0.05)$. There were no significant association between anti-HBs positivity and the size of household, education level, type of work, and type of settlement $(\mathrm{P}>0.05)$.

Multivariate logistic regression models showed that woman with older age (OR $=1.4 ; 95 \% \mathrm{CI}, 1.02-2)$, high 
Yentur Doni N et al.

\begin{tabular}{|c|c|c|c|c|c|c|c|}
\hline \multirow{2}{*}{ Independent Variables } & \multirow[t]{2}{*}{ B } & \multirow{2}{*}{ SE } & \multirow{2}{*}{ Wald } & \multirow{2}{*}{ P Value } & \multirow[t]{2}{*}{$\mathbf{E X},(\mathrm{B})$} & \multicolumn{2}{|c|}{ CI 95\% } \\
\hline & & & & & & Lower & Upper \\
\hline Women's Age ( $\geq 35 \mathrm{y})$ & 0.291 & 0.222 & 3.024 & 0.025 & 1.38 & 1.02 & 2.07 \\
\hline Number of Pregnancies $(\geq 5)$ & 0.200 & 0.233 & 3.957 & 0.047 & 1.22 & 1.02 & 1.93 \\
\hline $\begin{array}{l}\text { Place of Delivery (Birth at Home } \\
\text { Without Healthcare Professionals Aid) }\end{array}$ & 0.353 & 0.213 & 4.531 & 0.003 & 1.42 & 1.03 & 2.16 \\
\hline Constant & -3.902 & 0.348 & 126.038 & 0.000 & & & \\
\hline
\end{tabular}

a Abbreviations: B, B : This is the coefficient for the constant (also called the "intercept") in the null model; SE, These are the standard errors associated with the coefficients; and EX, ): The odds ratio for an independent variable.

parity (OR=1.2; 95\% CI,1.02-1.9), and delivery at home without healthcare professionals aid $(\mathrm{OR}=1.4 ; 95 \% \mathrm{CI}, 1.03-2.2)$ were more likely to have high anti-HBs levels (Table 5).

\section{Discussion}

To our knowledge, this study was the first to report the prevalence on representative reproductive-age female farmworkers, which aimed to estimate the at risk group in agricultural communities. The number of findings is highlighted by the Sanliurfa study. The prevalence of HBsAg positivity was 5.7\% among agricultural reproductive-age female farmworkers. Similar result were reported in a study (4.2\%) (15), while it was twice higher when compared to another study conducted in Turkey (11). In our study, anti-HBs positivity was determined in approximately one out of every four female farmworkers of childbearing age with a high prevalence of $25.9 \%$. Other serologic markers prevalence rates for anti-HBc total positivity, anti-HBe positivity, and seropositivity were $28.9 \%, 16.4 \%$, and $36.7 \%$, respectively. The findings of the present study indicated that the rate of anti-HBc positivity was higher than those of a previous study in Turkey (16). Moreover, anti-HBc was detected in $80 \%$ and anti-HBe in $75 \%$ of cases with HBsAg positivity. These findings were similar to those of population-based studies conducted in other regions of Turkey (17). On the other hand, the rates of HBsAg and anti-HBs positivity in this study were three times higher than those in studies on pregnant women in different Muslim countries and Southeastern Anatolia (18-20). In this study, the prevalence of hepatitis $\mathrm{B}$ was higher than that of a study reporting a prevalence rate of $1.3 \%$ in the general population of Central Iran (21). This difference might be due to the living conditions related to the occupation. Thus, our study might appear in line with the estimate that considered Turkey as a country with intermediate endemicity for hepatitis B. Horizontal transmission was an important risk factor, particularly among farmworkers with a low socioeconomic status. In our study, $64.9 \%$ of the female farmworkers' families had at least seven members. We observed that the study areas in which female farmworkers live in represent the same features as other developing countries, ie, low socioeconomic status, poor hygiene, and crowded households, where hepatitis $\mathrm{B}$ is endemic. Moreover, families living in overcrowded conditions and those far from the health services might be at a higher risk of hepatitis $B$ infection $(3,10,11,22)$. According to the age-specific prevalence of HBsAg positivity, we found the lowest prevalence in the age group of 15 to 24 years (4.5\%), which might be the result of a national vaccination program for the prevention of perinatal transmission of hepatitis B infection, launched in Turkey in 1998 by the Turkish Ministry of Health (23). In our study, seasonal female farmworkers were the major at-risk group for HBsAg positivity. The rate of hepatitis B infection was 4.2-times higher in seasonal farmworkers than in female family farmworkers. This might be explained by the obstacles to access healthcare services, unhealthy and substandard living conditions, and movement from one place to another.

In our study, the type of settlement was another significant risk factor for HBsAg positivity. Female farmworkers living in urban slum areas had a higher infection rate of hepatitis B than female farmworkers living in villages did. This might be related to the underserved population in slums and their exposure to unhealthy conditions. In this study, other risk factors included higher parity and the place of delivery for female farmworkers. Women with $\geq 5$ pregnancies who did not receive healthcare professionals' aid were more often infected with hepatitis B. This might be related to the limited access to healthcare services, using unhealthy and contaminated devices, and traditional methods during birth.

In our study, educational attainment was not associated with hepatitis $\mathrm{B}$, which might be due to the distribution of the female farmworkers' education levels. In our study, $68.1 \%$ of the female farmworkers were illiterate and others attended only primary school or higher. Thus, there was no significance difference according to educational levels. We noticed that primary school was not enough for changing the attitude for preventing, controlling, and raising awareness about hepatitis B as a source of infection.

\subsection{Strengths and Limitations}

The results of the present study should be interpreted in the light of a number of limitations. First, as this study involved a cross-sectional household interview survey, it might be impossible to draw conclusions about the na- 
ture of the putative causal relationship between hepatitis B and independent variables. Despite this limitation, the present study identified the prevalence and at-risk groups in reproductive-age women farmworkers, according to WHO recommendations to control the disease. Older age, seasonal migratory farmworker, high parity, living in slums, and delivery at home or field without health professional assistance were risk factors of contracting HBV infection. Despite the limitation in the design of this study, the results of this study had immediate practical implications for improvement of the Hepatitis B control.

Secondly, additional analytic-epidemiologic researches are needed to replicate these findings and to investigate the potential underlying mechanisms that could explain the differential association of HBV infection and risk factors. The high prevalence rate highlighted by this study reflects a profound primary healthcare services gap. There is an urgent need for the development of integrated interventions to reduce risk factors as well as to strengthen protective factors to control hepatitis B infection. These recommended systematic and institutional steps are needed to control of the disease:

1) enhanced surveillance systems to gather and analyze data for the identification and monitoring of risk groups; 2) intersectoral approaches to reduce health inequalities and living conditions; 3 ) undergraduate medical education and in-service training for primary healthcare staff to provide better health services in the agricultural population, specifically targeting seasonal female farmworkers of between 15 and 49 years of age; and 4) the healthcare system should follow up with all female farmworkers in the fields and primary care activities should be provided by mobile health services, including laboratory analyzing support, screening, vaccination, and health education programs (24). All of these domains would be of vital importance for prevention and intervention measures in control of hepatitis B.

\section{Acknowledgements}

The authors express their thanks to the Harran University Scientific Council and GAP Regional Development Administration for supporting the research, and all female farmworkers for participating.

\section{Authors' Contributions}

Study concept and design: Nebiye Yentur Doni and Zeynep Simsek; acquisition of data: Nebiye Yentur Doni, Zeynep Simsek, Zehra Keklik, and Gulcan Gurses; analysis and interpretation of data: Zeynep Simsek and Nebiye Yentur Doni; drafting the manuscript: Zeynep Simsek, Nebiye Yentur Doni, Zehra Keklik, Gulcan Gurses, and Fadile Yildiz Zeyrek; critical revision of the manuscript for important intellectual content: Nebiye Yentur Doni, Zeynep Simsek, and Fadile Yildiz Zeyrek; statistical analysis: Nebiye Yentur Doni and Zeynep Simsek; Administra- tive, technical, and material support: Nebiye Yentur Doni, Zeynep Simsek, Zehra Keklik, Gulcan Gurses, and Fadile Yildiz Zeyrek; and study supervision: Nebiye Yentur Doni, Zeynep Simsek, Zehra Keklik, Gulcan Gurses, and Fadile Yildiz Zeyrek.

\section{Funding/Support}

This study was funded by Harran University Scientific Council and SAP Regional Development Administration.

\section{References}

1. Hope VD, Eramova I, Capurro D, Donoghoe MC. Prevalence and estimation of hepatitis B and C infections in the WHO European Region: a review of data focusing on the countries outside the European Union and the European Free Trade Association. Epidemiol Infect. 2014;142(2):270-86.

2. World Health Organisation.. Prevention and control of viral hepatitis infection: frame work for global action: Framework for Global Action. 2012. Available from: http://www.who.int/csr/disease/ hepatitis/Framework/en/.

3. Goldstein ST, Zhou F, Hadler SC, Bell BP, Mast EE, Margolis HS. A mathematical model to estimate global hepatitis B disease burden and vaccination impact. Int J Epidemiol. 2005;34(6):1329-39.

4. Mahoney F, Kane M. Hepatitis B vaccine, Vaccines. 3rd edPhiladelphia: W.B. Saunders Company; 1999.

5. Lewis-Ximenez LL, do OK, Ginuino CF, Silva JC, Schatzmayr HG, Stuver S, et al. Risk factors for hepatitis B virus infection in Rio de Janeiro, Brazil. BMC Public Health. 2002;2:26.

6. Toy M, Onder FO, Wormann T, Bozdayi AM, Schalm SW, Borsboom GJ, et al. Age- and region-specific hepatitis B prevalence in Turkey estimated using generalized linear mixed models: a systematic review. BMC Infect Dis. 2011;11:337.

7. International Labour Organization.. Agriculture; plantations; other rural sectors. 2014. Available from: http://www.ilo.org/global/ industries-and-sectors/agriculture-plantations-other-rural-sectors/lang--en/index.htm.

8. Turkish Statitical Institue.. Address Based Population Registration System Results. 2012. Available from: http://www.turkstat.gov.tr Start.do.

9. World Health Organisation.. Global Alert and Response (GAR) Hepatitis B. 2002. Available from: http://www.who.int/csr/disease/ hepatitis/whocdscsrlyo20022/en/index3.html\#risk.

10. Howell J, Lemoine M, Thursz M. Prevention of materno-foetal transmission of hepatitis B in sub-Saharan Africa: the evidence, current practice and future challenges. J Viral Hepat. 2014;21(6):381-96.

11. Altay T, Uskun E, Akcam FZ. Seroprevalence of hepatitis B surface antigen and its correlation with risk factors among new recruits in Turkey. Braz J Infect Dis. 2012;16(4):339-44.

12. Simsek Z. [The research of the health of those who work in my GAP agriculture]. 2014:22-3.

13. Hollinger F, Liang T. Hepatitis B Virus. In: Knipe DM, et al. editors. Fields Virology. 4th ed. Philadelphia: Lippincott Williams \& Wilkins; 2001.

14. Van Damme P, Kane M, Meheus A. Integration of hepatitis B vaccination into national immunisation programmes. Viral Hepatitis Prevention Board. BMJ.1997;314(7086):1033-6.

15. TEKIN KORUK, S. , KORUK Bensu GÜRSOY, I. , ÇALIȘIR, C. , YÜKSEL, F , YILDIZ ZEYREK, F. , ȘIMSSEK, Z. . [Hepatitis B and Hepatitis C Seroprevalence in the Center of Sanliurfa Province From Southeastern Anatolia Region and Related Risk Factors]. Trakya Univ Tip Fak Derg. 2010;27(4):367-72.

16. Koten F,, Oztop F, Engin A. [Investigation of the HBV DNA in isolated hepatitis B core antibody positive blood donors]. Sci Res Essays. 2011;6(13):2720-3.

17. Mistik R, Balik I. The epidemiologic analysis of the viral hepatitis in Turkey. In: Tekeli E, Balik I editors. Viral Hepatitis.. Ankara:VHSD (The Organization of War with Viral Hepatitis); 2003. pp. 10-55. 


\section{Yentur Doni N et al.}

18. Al Awaidy S, Abu-Elyazeed R, Al Hosani H, Al Mulla A, Al Busaiedy S, Al Amiry A, et al. Sero-epidemiology of hepatitis B infection in pregnant women in Oman, Qatar and the United Arab Emirates. J Infect. 2006;52(3):202-6.

19. Todd CS, Ahmadzai M, Atiqzai F, Miller S, Smith JM, Ghazanfar SA, et al. Seroprevalence and correlates of HIV, syphilis, and hepatitis $B$ and $C$ virus among intrapartum patients in Kabul, Afghanistan. BMC Infect Dis. 2008;8:119.

20. Araz NC, Dikensoy E. Seroprevalence of hepatitis B among pregnant women in southern Turkey. J Pak Med Assoc. 2011;61(2):176-7.

21. Ghadir MR, Belbasi M, Heidari A, Jandagh M, Ahmadi I, Habibinejad $\mathrm{H}$, et al. Distribution and risk factors of hepatitis B virus infection in the general population of Central Iran. Hepat Mon. 2012;12(2):112-7.

22. Mehmet D, Meliksah E, Serif Y, Gunay S, Tuncer O, Zeynep S. Prevalence of hepatitis B infection in the southeastern region of Turkey: comparison of risk factors for HBV infection in rural and urban areas. Jpn J Infect Dis. 2005;58(1):15-9.

23. Uyar Y, Cabar C, Balci A. Seroprevalence of Hepatitis B Virus among Pregnant Women in Northern Turkey. Hepat Mon. 2009;9(2):146-9.

24. Simsek Z, Koruk I, Doni NY. An operational study on implementation of mobile primary healthcare services for seasonal migratory farmworkers, Turkey. Matern Child Health J. 2012;16(9):1906-12. 